\title{
Connected Health Living Lab ${ }^{\dagger}$
}

\author{
Elizabeth Martin ${ }^{1}$, Ian Cleland ${ }^{1}$, Chris Nugent 1,* , Claire Orr ${ }^{1}$, Tanya McCance ${ }^{2}$, \\ Assumpta Ryan ${ }^{2}$ and Jim McLaughlin ${ }^{3}$ \\ 1 School of Computing, Ulster University, 16G14 Jordanstown, Newtownabbey BT37 0QB, UK; \\ e.martin@ulster.ac.uk (E.M.); i.cleland@ulster.ac.uk (I.C.); c.orr@ulster.ac.uk (C.O.) \\ 2 School of Nursing, Ulster University, 12J10 Jordanstown, Newtownabbey BT37 0QB, UK; \\ tv.mccance@ulster.ac.uk (T.M.); aa.ryan@ulster.ac.uk (A.R.) \\ 3 School of Engineering, Ulster University, 25B16 Jordanstown, Newtownabbey BT37 0QB, UK; \\ jad.mclaughlin@ulster.ac.uk \\ * Correspondence: cd.nugent@ulster.ac.uk \\ + Presented at the 13th International Conference on Ubiquitous Computing and Ambient Intelligence \\ UCAmI 2019, Toledo, Spain, 2-5 December 2019.
}

Published: 20 November 2019

\begin{abstract}
The school of computing, in collaboration with the institute of nursing and health research and the school of engineering, recently established the connected health living lab (CH:LL) at Ulster University. CH:LL offers a dedicated environment to support user and clinical engagement, access to state-of-the-art technology to assess usability and interaction with innovative technologies, in addition to being a dedicated environment to record user behaviours with new connected health solutions. The creation of such a dedicated environment offers a range of benefits to support multidisciplinary research in the area of connected health. This paper illustrates the design, development, and implementation of CH:LL, including a description of the various technologies associated with the living lab at Ulster University. To conclude, the paper highlights how these resources have been used to date within various research projects.
\end{abstract}

Keywords: living lab; connected health; smart environments; usability; evaluation

\section{Introduction}

Research in the field of smart environments has been a core research theme within the school of computing at Ulster University for more than 15 years. Over this time, research activities have focused on addressing the challenges associated with ageing, including those suffering from long term chronic conditions and the general theme of promoting healthy lifestyles. Although not being claimed as the definitive solution, the use of technology is being widely recognised as having a significant role to play within these topical areas. The increased prevalence of technology usage, its reduced costs, improved processing, and communication speeds are all key factors which have resulted in new technology-based solutions being investigated within the realms of smart environments [1].

There is a growing need to engage with users in the design and development of technologybased solutions [2]. Through designing with users rather than for them, digital platforms can be tailor-made to help address specific needs and expectations. This is a key, as co-design is essential to ensure that developed technology is fit for purpose and can be successfully adopted [2].

Living labs allow a form of experimental governance, whereby stakeholders develop and test new technologies and ways of living to address the challenges associated with the elderly and persons with various cognitive ailments [3]. This involves staging intentional experiments in realworld settings which are then monitored and learnt from [4]. 
Through collaboration with the department for the economy, coupled with the health and social care research and development office, funding was secured for a living lab within the Ulster University, Jordanstown campus. The lab was designed to support the development of connected health solutions within the University and local industry in Northern Ireland. The lab has now been operational since May 2019.

In order to maximise the impact of the connected health living lab (CH:LL) we have begun discussions with other living labs across Europe, namely the smart lab at University of Jaen (Spain) [5], the human health and activity laboratory, Lulea (Sweden) [6], and Halmstad intelligent home at Halmstad University (Sweden) [7]. This network of living labs, facilitated through the Horizon 2020 project REMIND, will allow for the sharing of best practices in the design and evaluation of connected health solutions, in addition to allowing developed solutions to be evaluated with an international cohort.

The remainder of this paper provides a brief overview of what living labs are, along with the design and development of our own living lab at Ulster University. State-of-the-art technologies and their uses are further explained, coupled with various projects that have all made use of our living lab resources.

\section{Background}

Observations and recordings can be made through the use of a living lab, which can offer true to life scenarios, allowing clinicians and researchers a better understanding of an individual's needs [8]. This can be illustrated by observing a participant completing a number of activities in real time, in a setting familiar to their own home, rather than have them complete a series of generic tick boxes.

In a study by Westerlund and Leminen (2012) [9], they describe living labs as "physical regions or virtual realities, or interaction spaces, in which stakeholders form public private-people partnerships (4Ps) of companies, public agencies, universities, users, and other stakeholders, all collaborating for creation, prototyping, validating, and testing of new technologies, services, products, and systems in real-life contexts".

The European network of living labs (ENoLL) is the international federation of benchmarked living labs in Europe and globally [10]. ENoLL is a worldwide network of living labs that puts people at the front and centre of their product service and development [10]. ENoLL also offer user engagement, test and experimentation facilities targeting novel methods including mobility, healthcare, energy, to name but a few. Therefore, ENoLL is positioned to be a platform for best practice exchange, learning and support, and living lab international project development [10].

There are various living labs, including living lab Eindhoven (Netherlands) [11], Imec living labs (former iMinds living labs) (Belgium) [12], Laurea (Finland) [13], and the living lab at Manchester University [14] are just a few of the key research facilities that have been studied.

\section{Living Lab at Ulster University}

CH:LL, within the school of computing at Ulster, provides a unique environment to support multi-disciplinary research in the area of connected health. CH:LL leverages research expertise in the creation, development, and evaluation of cutting-edge technologies. This includes vast experience in usability and human computer interaction. This expertise is combined with state-of-the-art facilities in usability assessment, vital signs monitoring, mobile and wearable computing, virtual and augmented reality. The lab provides the following opportunities:

- A dedicated environment to support user and clinical engagement in the development and evaluation of connected health solutions.

- Access to state-of-the-art resources to assess usability and interactivity with innovative connected health solutions.

- An opportunity to establish the processes governed by the medicines and healthcare products regulatory agency (MHRA) and general data protection regulation (GDPR) in software development for connected health solutions. 
- A dedicated environment to observe naturalistic user behaviours with new connected health solutions.

- An appealing space to facilitate public engagement and patient public involvement (PPI)-related events.

The living lab provides an infrastructure to facilitate a user-centred, open innovation ecosystem, integrating research and innovation within a public-private-people partnership delivered through an iterative experiential design process. This provides a unique opportunity to engage in multidisciplinary and intersectoral co-creation, thus strengthening civic engagement and the opportunities for creating innovative solutions.

\subsection{Design of Living Lab}

It was envisaged that the proposed lab area would have facilities similar to those outlined in Figures 1 and 2. These included a large reconfigurable seating/ discussion area, private booth areas for eye tracking and brain computer interface $(\mathrm{BCI})$ experiments, a virtual immersive environment for research into virtual and augmented reality, and a control room (hidden by one-way mirror) to both observe participants and house monitoring equipment.

Within the physical design of the living lab, effort has been focused on the design and procurement of a flexible/reconfigurable environment based on a modular building block solution. The team have been engaging with Everblocks [15], a modular building solution (Figure 3) to understand how this innovative solution can be used to facilitate the various private spaces and control areas required to implement the living lab spaces. The reconfigurable space includes a oneway mirror to observe the participants and create a private area for storage of monitoring equipment. To capture user interaction with the technology, a CCTV system based on four pan, tilt, and zoom cameras have been installed. This solution can record back to the control centre behind the one-way mirror and allows capture of all elements of the user interaction undertaken in the environment. Figure 4 illustrates the Everblocks used within the living lab.

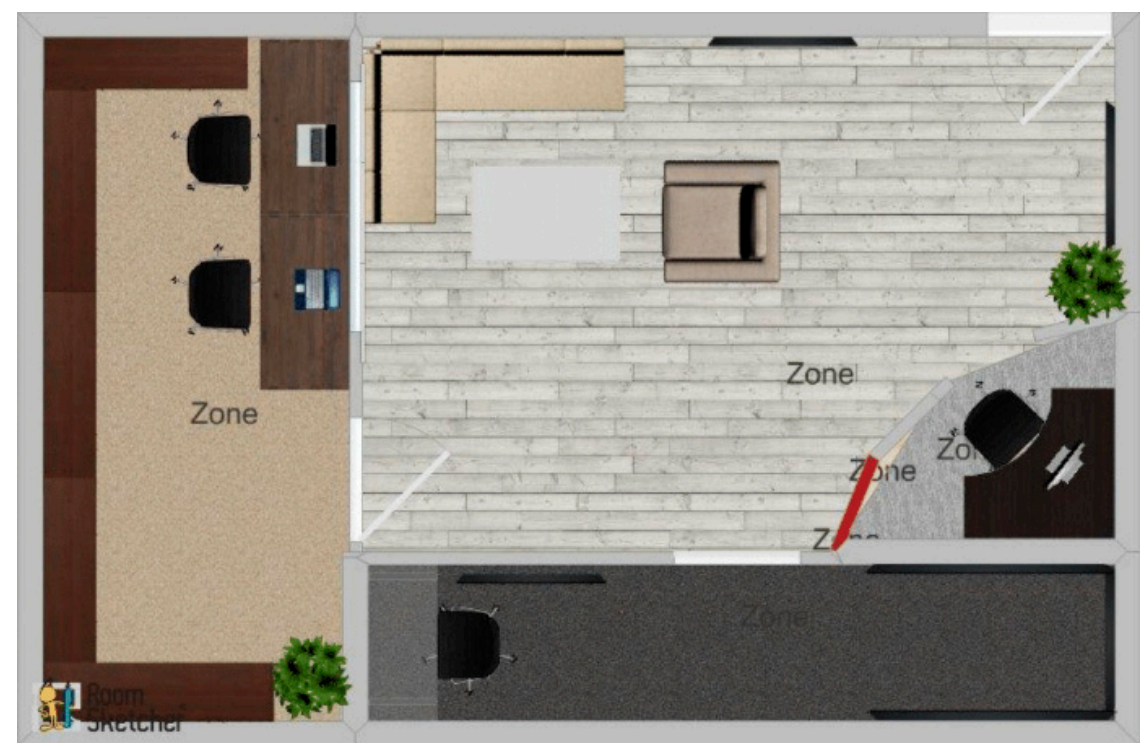

Figure 1. Original floor plans for our living lab. 


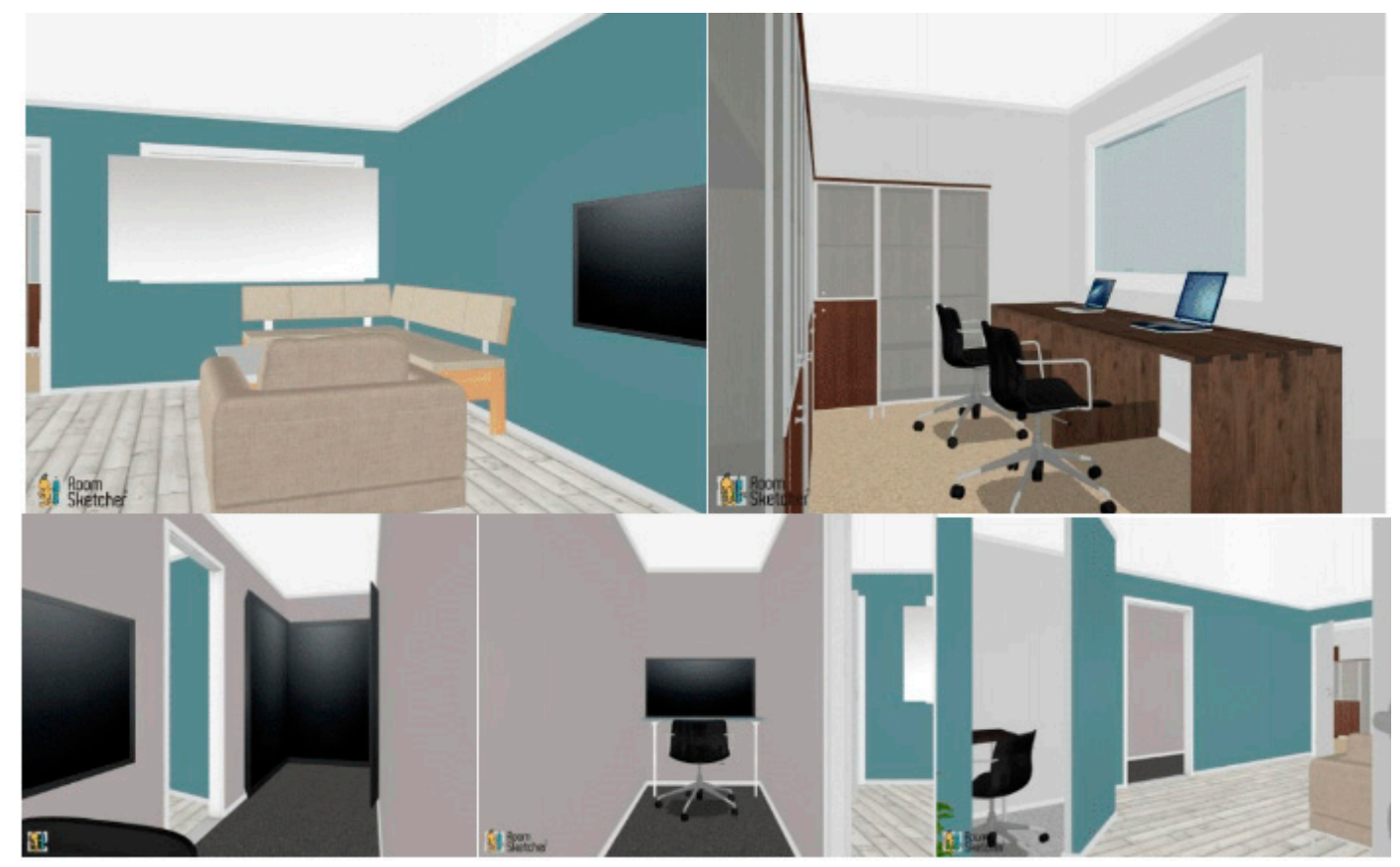

Figure 2. Initial 3D sketches of our living lab.

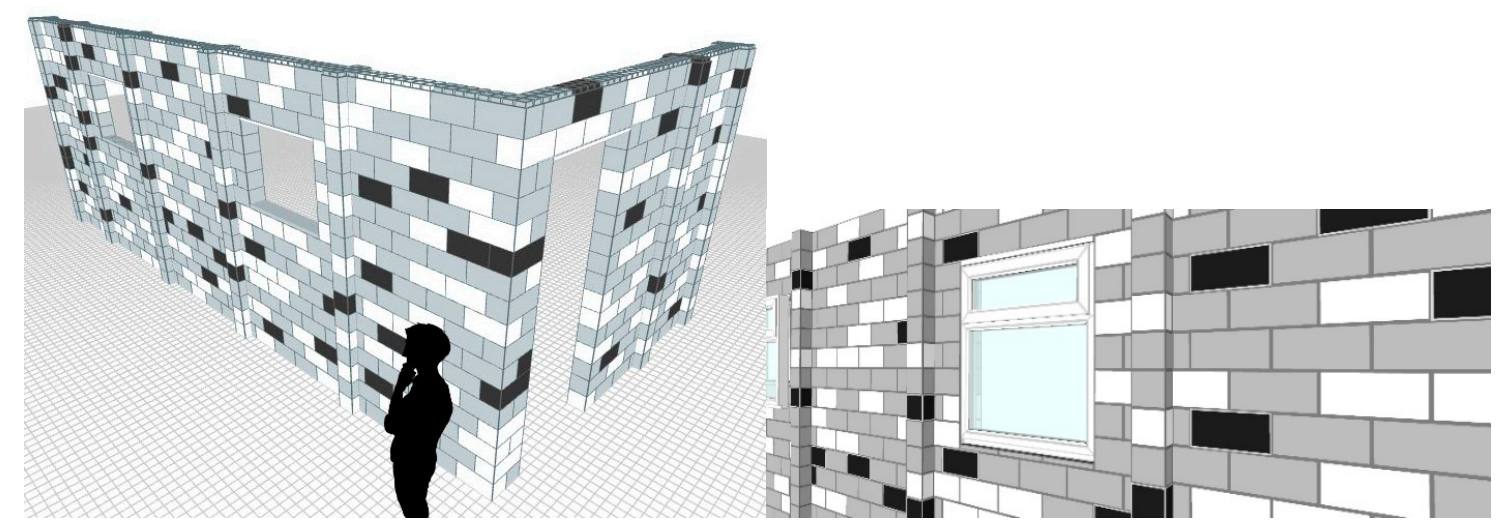

Figure 3. Desgin documentation of the modular building block solution designed and procured from Everblocks. This has facilitated the development of the living lab.

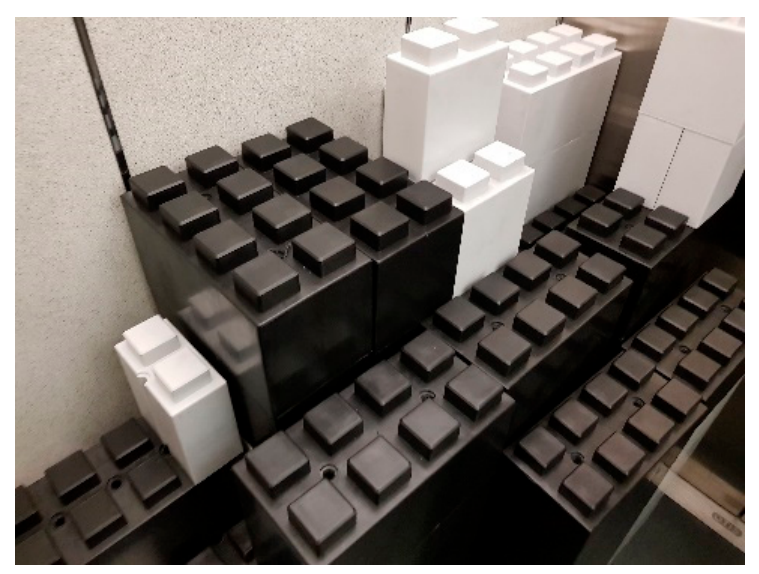

Figure 4. Everblocks unboxed and awaiting assembly in the living lab. 


\subsubsection{State-of-the-Art Technology}

The living lab includes state-of-the-art technologies which can be used to assess usability and offers participants various interactions. To date, this task has focused on the procurement and configuration of sensing equipment to monitor galvanic skin response (GSR), heart rate (HR) (Figure 5), electroencephalography (EEG), eye tracking, and gross physical movement. The living lab is fully functional and makes use of a suite of technology. This includes $4 \times$ Emotive Epoch EEG caps, $4 \times$ Empatica e4 (GSR/heart rate sensors), $4 \times$ Shimmer GSR sensor, and associated software. Simulation tools have also been purchased to allow clinical situations to be replicated. This includes customised human geometry hardware and associated Labview biomedical toolkit. Additionally, a state-of-theart solution for eye-tracking (Figure 6) (Tobii Pro Glasses 2,) has been procured and is currently being evaluated in a number of use cases, including sport analysis, driver alertness, and transport. To process and store the vast amount of data that can be generated by this technology, we have procured a high spec server which has now been configured to collect and store this data. To complement this, a data annotation tool (DANTE) has been procured and configured. This tool will allow for annotation of the data collected from the sensor solutions which can then be appropriately interpreted and inference can be drawn.
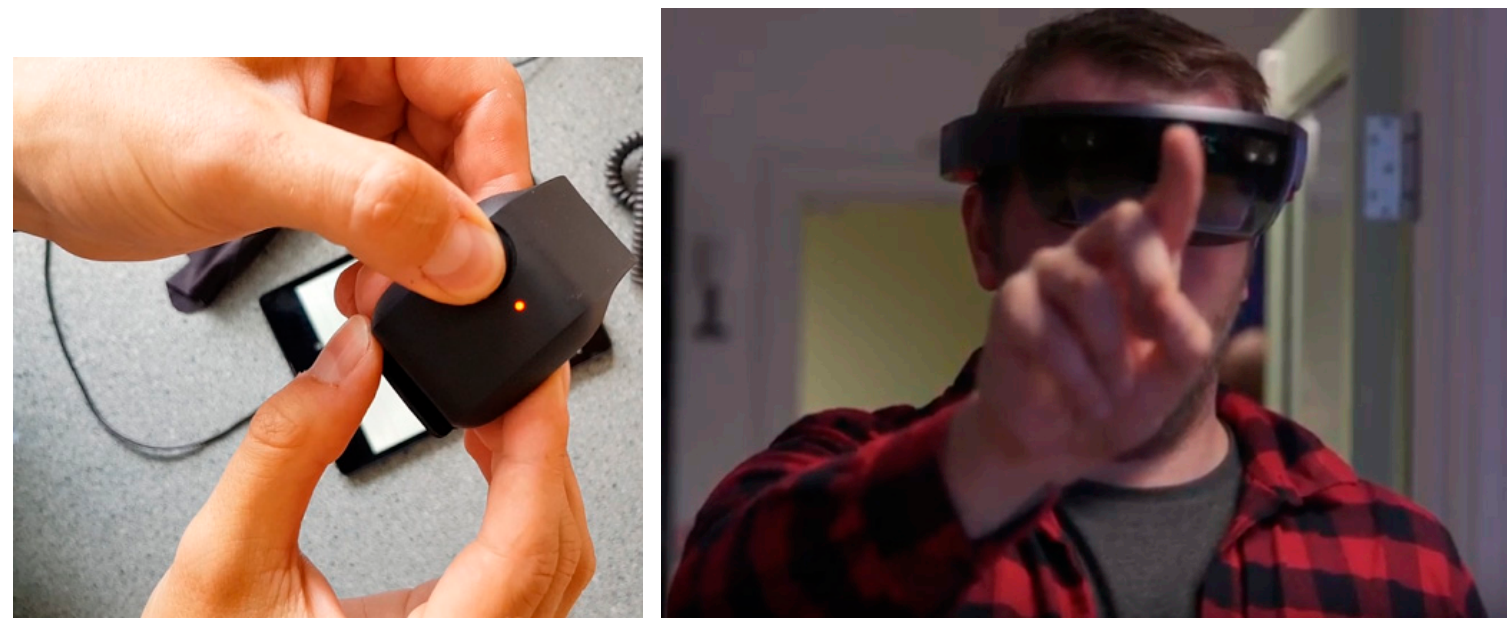

Figure 5. Shows the Empatica E4 heart rate and galvanic skin response (GSR) sensor (Left) and augmented reality solution (Right).

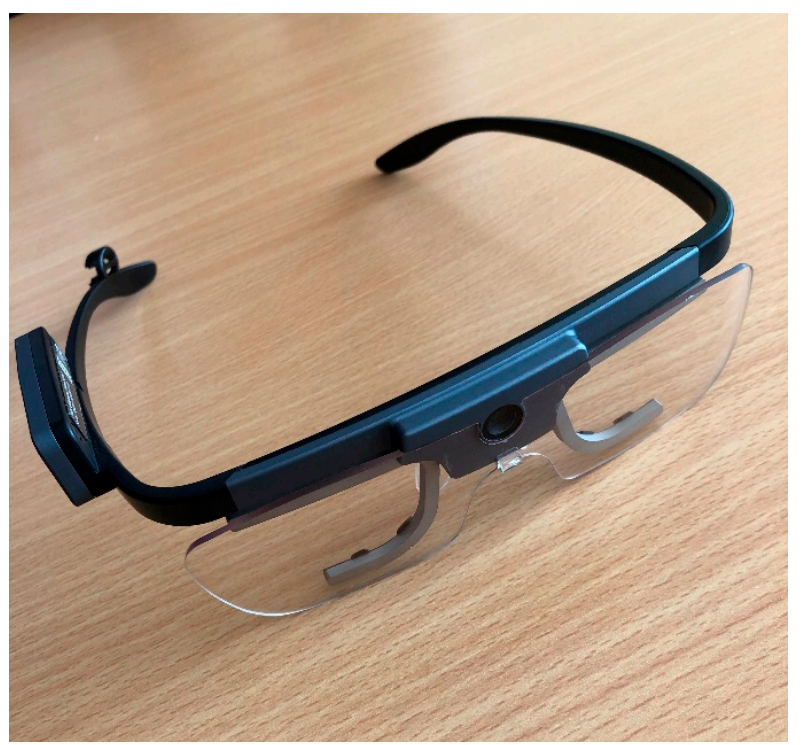

Figure 6. Shows the Tobii eye tracking glasses. 


\subsubsection{Recording User Behaviours}

In addition to the procurement of the reconfigurable modular, as described in Section 3.1, additional equipment and resources have been procured to allow for the recording of user behaviour in engagement with m-health apps. This includes a number of tablet and high spec personal computers. Additionally, interactive technologies, including virtual reality equipment and Oculus Go (refer to Figure 7), and tele-presence devices have been procured. Table 1 offers a breakdown on how we use the various technology within the living lab (Figure 8).

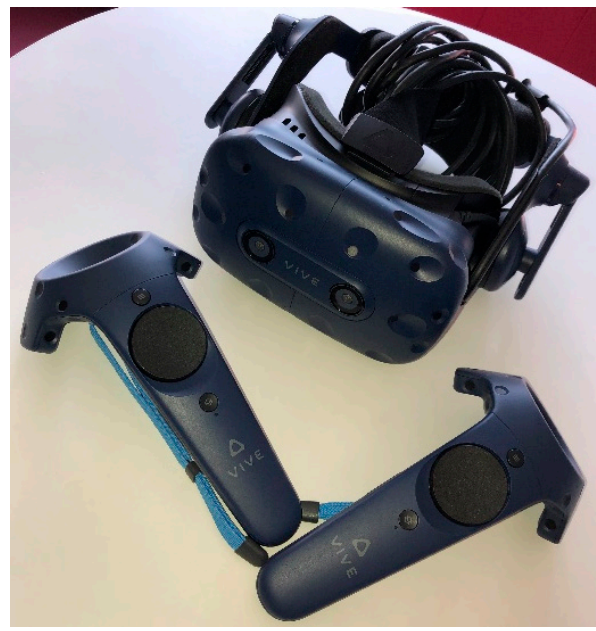

(a)

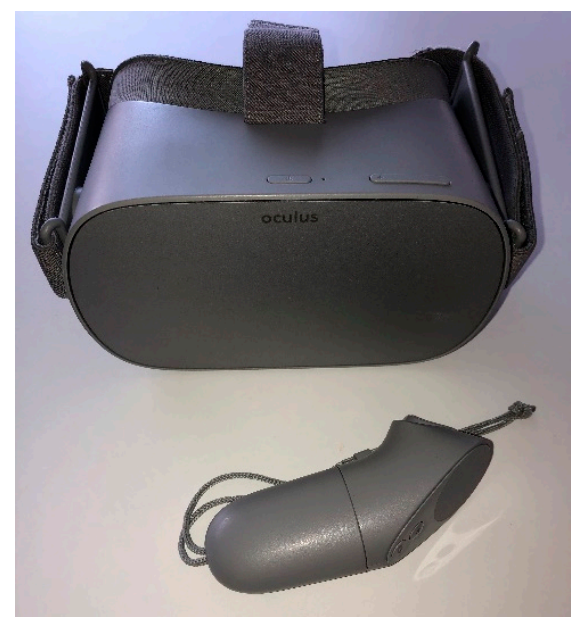

(b)

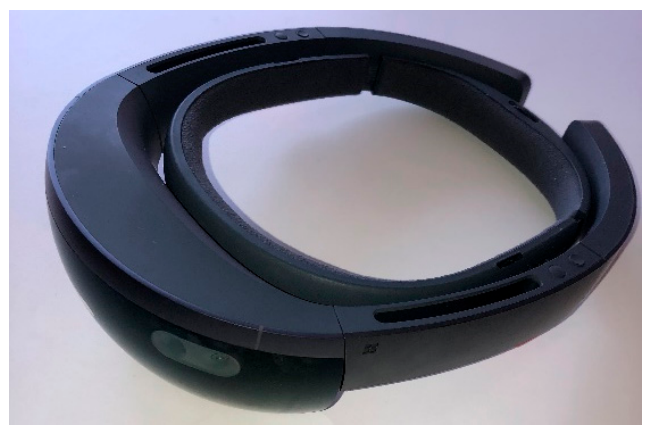

(c)

Figure 7. Images of the virtual reality and augmented reality headsets. (a) illustrates the VIVE headset and controllers, (b) shows the Oculus headset and controller with (c) dipicting the Hololens.

Table 1. Technology within the living lab.

\begin{tabular}{lll}
\hline Technology: & $\begin{array}{l}\text { Areas of User } \\
\text { Interaction: }\end{array}$ & How It Is Used within the Living Lab: \\
\hline iPads & $\begin{array}{l}\text { Communication } \\
\text { Tool }\end{array}$ & $\begin{array}{l}\text { Information collected through the iPad is sent and stored on a sever for } \\
\text { data analysis. Participants can complete with either one or two hands, } \\
\text { whichever is comfortable to them. }\end{array}$ \\
\hline $\begin{array}{l}\text { HTC Vive } \\
\text { Pro }\end{array}$ & Virtual Reality & $\begin{array}{l}\text { Fully submersive experience, can allow the participant to move around } \\
\text { a pre-defined area and perform tasks using the two handheld } \\
\text { controllers. }\end{array}$ \\
\hline $\begin{array}{l}\text { Oculus } \\
\text { headset }\end{array}$ & Virtual Reality & $\begin{array}{l}\text { Offers the participant to a virtual experience whilst sat stationary. A } \\
\text { number of 'scenes' can be selected for viewing, along with video clips } \\
\text { that play back and viewed in 3D. }\end{array}$ \\
\hline $\begin{array}{l}\text { Hololens } \\
\text { Tobii Eye } \\
\text { Tracker }\end{array}$ & Augmented & $\begin{array}{l}\text { Enables mapping and overlaying of images in real time. Participants } \\
\text { can 'design' a room by leaving a series of digital images suspended in } \\
\text { augmented reality and viewable through the headset. }\end{array}$ \\
\hline
\end{tabular}




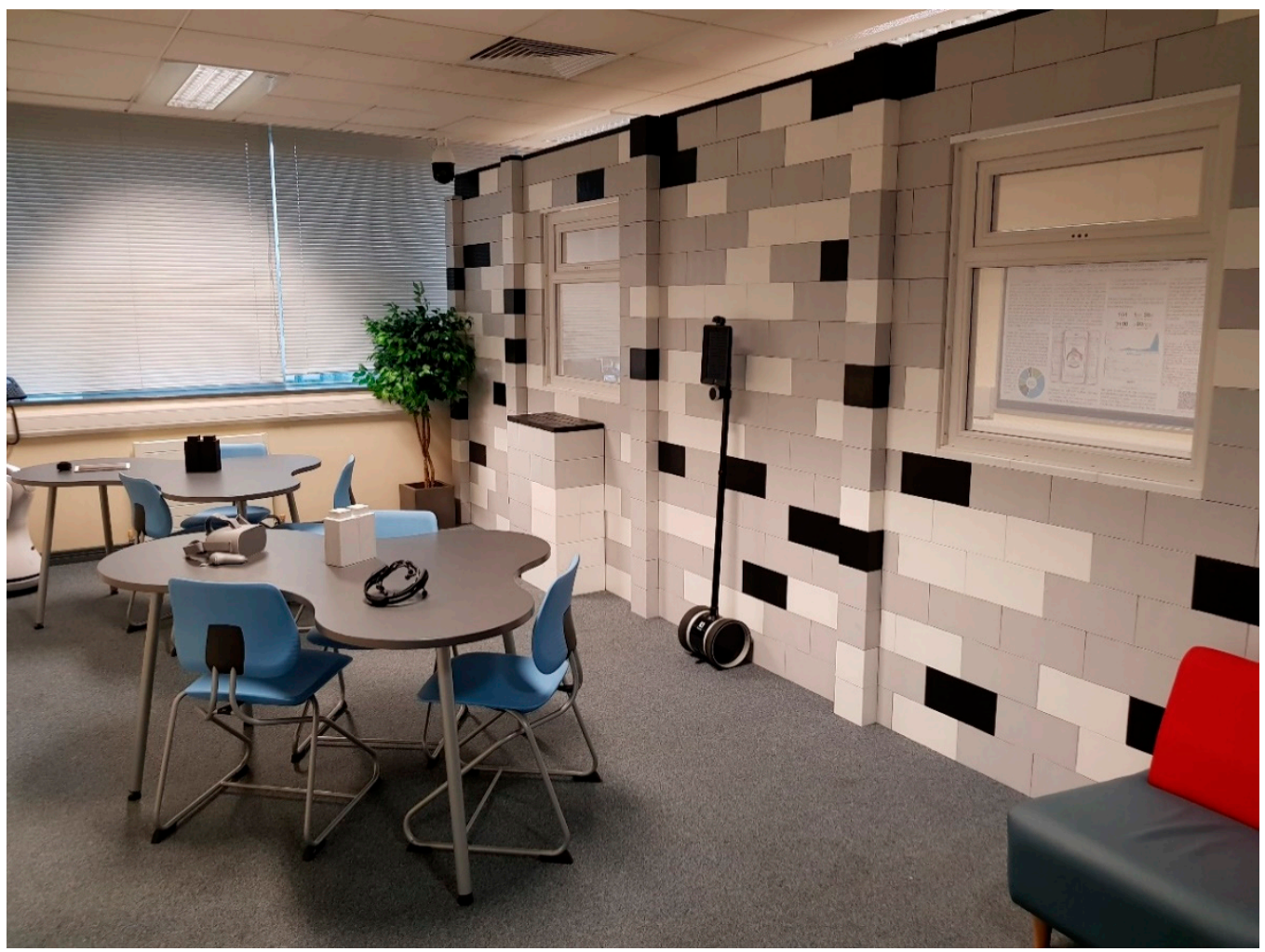

Figure 8. Shows the completed living lab setup within the smart environment research group (SERG).

\section{Case Studies}

To date, the living lab has been used by six cross-disciplinary collaborative projects. See Table 2 for full details of all projects.

Table 2. Collaborative project involving the living lab.

\begin{tabular}{|c|c|}
\hline Project Name & Description \\
\hline iMPAKT: & $\begin{array}{l}\text { Implementing and measuring person centredness using an app for knowledge is } \\
\text { a multidisciplinary project between the institute of nursing and health research } \\
\text { and school of computing at Ulster. It is developing an app to measure person } \\
\text { centeredness from nursing staff, initially in cancer care services. The project has } \\
\text { been using the living lab during the design phase of the project to ensure } \\
\text { usability of the app is maximised. The project is being funded by MacMillian. }\end{array}$ \\
\hline $\begin{array}{l}\text { Connected } \\
\text { Health Living } \\
\text { Lab (CHIC)- }\end{array}$ & $\begin{array}{l}\text { CHIC has been using facilities within the living lab for a number of its } \\
\text { multidisciplinary industry focused projects. In particular, CHIC has hosted PPI } \\
\text { events within the lab for the development of a technology solution for the } \\
\text { detection and prevention of diabetic foot disease. Researchers have held two } \\
\text { events within the lab where end users have collected thermal images of their } \\
\text { feet using a mobile thermal imaging solution, developed within the project. In } \\
\text { total, over } 22 \text { participants have engaged through this project. }\end{array}$ \\
\hline $\begin{array}{l}\text { BT Ireland } \\
\text { Innovation } \\
\text { Centre } \\
\text { (BTIIC)- }\end{array}$ & $\begin{array}{l}\text { The BTIIC project, a collaboration between BT Ireland and Ulster University, } \\
\text { has been making use of the state-of-the-art eye tracking technologies offered } \\
\text { through the living lab. These technologies are being used to measure and } \\
\text { improve the usability of the company's YouView set top box. }\end{array}$ \\
\hline $\begin{array}{l}\text { Dyslexia in } \\
\text { Programmers }\end{array}$ & $\begin{array}{l}\text { Eye tracking technologies, procured through the lab, are also being used to } \\
\text { measure differences in how computer science students read code. }\end{array}$ \\
\hline $\begin{array}{l}\text { Brain } \\
\text { Computer }\end{array}$ & $\begin{array}{l}\text { The environment is being used as an environment to undertake testing and } \\
\text { research into the development of brain computer interface technologies. This }\end{array}$ \\
\hline
\end{tabular}




\begin{tabular}{ll}
\hline $\begin{array}{l}\text { Interface } \\
\text { Study }\end{array}$ & $\begin{array}{l}\text { testing requires a private and quiet environment in which to undertake testing. } \\
\text { In addition, this project is utilising the Emotiv epoch BCI caps purchased } \\
\text { through this project. }\end{array}$ \\
\hline & $\begin{array}{l}\text { In order to maximise the impact of CH:LL we have begun discussions with other } \\
\text { living labs across Europe, namely the smart lab at University of Jaen (Spain), the }\end{array}$ \\
human health and activity laboratory, Lulea (Sweden), and Halmstad intelligent \\
ProjinD & $\begin{array}{l}\text { home at Halmstad University (Sweden). This network of living labs, facilitated } \\
\text { through the Horizon 2020 project REMIND, will allow for the sharing of best } \\
\text { practices in the design and evaluation of connected health solutions, in addition } \\
\text { to allowing developed solutions to be evaluated with an international cohort. }\end{array}$ \\
\end{tabular}

\section{Conclusions}

The CH:LL is aimed at building capacity for user engagement and usability assessment in the design and evaluation of connected health solutions. This is something that is increasingly needed to improve the demand of such technologies. Furthermore, user engagement is considered as an essential part of the co-creation process of these technologies and is increasingly sought for by funders of large societal grants, including Horizon 2020 and research council funding. This project has already attracted great interest across the three faculties and will strengthen multidisciplinary research in the area of connected health.

New partnerships are being developed through collaborative funding applications, as described in D3.3. Additionally, existing projects using the facilities provided by the CHLL has allowed us to strengthen existing collaborations with various schools within the University, as well as commercial partners, such as BT.

To publicise the living lab, a suit of publicity materials is being developed. These include a video, flyers, and website. Presentations on the capabilities within the living lab have been provided at local "age-friendly innovation workshop" and international conference on ubiquitous computing and ambient intelligence conferences. Future collaboration will seek to collect data across three European living labs in Spain, Sweden, and Northern Ireland using a common protocol.

Author Contributions: All authors have contributed to the work presented (e.g., Conceptualization, Methodology, Software, Validation, Formal Analysis, Investigation, Resources, Data Curation, WritingOriginal Draft Preparation, Writing-Review and Editing, Visualization, Supervision, Project Administration, and Funding Acquisition).

Funding: The connected health living lab is funded by the department for economy and health and social care research and development office Northern Ireland.

Conflicts of Interest: The founding sponsors had no role in the design of the study; in the collection, analyses, or interpretation of data; in the writing of the manuscript, and in the decision to publish the results.

\section{References}

1. Ulster University, Pervasive Computing. Available online: https://www.ulster.ac.uk/research/topic/computerscience/centres/pervasive-computing/about (accessed on the 18 September 2019).

2. Digital Principles. Available online: https://digitalprinciples.org/principle/design-with-the-user/ (accessed 20 September 2019).

3. Colomer, J.B.; Salvi, D.; Cabrera-Umpierrez, M.F.; Arredondo, M.T.; Abril, P.; Jimenez-Mixco, V.; GarcíaBetances, R.; Fioravanti, A.; Pastorino, M.; Cancela, J.; et al. Experience in evaluating AAL solutions in living labs. Sensors (Basel) 2014, 14, 7277-7311. doi:10.3390/s140407277.

4. Voytenko, Y.; McCormick, K.; Evans, J.; Schliwa, G. Exploring urban living labs for sustainability and low carbon cities in Europe. J. Clean. Prod. 2015, 123, doi:10.1016/j.jclepro.2015.08.053.

5. Espinilla, M.; Martínez, L.; Medina, J.; Nugent, C. The Experience of Developing the UJAmI Smart Lab. IEEE Access 2018, 6, 34631-34642. doi:10.1109/ACCESS.2018.2849226. 
6. Synnes, K.; Lilja, M.; Nyman, A.; Espinilla, M.; Cleland, I.; Comas, A.G.S.; Comas-Gonzalez, Z.; Hallberg, J.; Karvonen, N.; Morais, W.O.; et al. $\mathrm{H}^{2} \mathrm{Al}$-The Human Health and Activity Laboratory. Proceedings 2018, 2, 1241.

7. Lundström, J.; de Morais, W.O.; Menezes, M.; Gabrielli, C.; Bentes, J.; Sant'Anna, A.; Synnott, J.; Nugent, C. Halmstad Intelligent Home-Capabilities and Opportunities. In Internet of Things Technologies for HealthCare. HealthyIoT 2016; Lecture Notes of the Institute for Computer Sciences, Social Informatics and Telecommunications Engineering; Ahmed, M., Begum, S., Raad, W., Eds.; Springer: Cham, Switzerland, 2016; Volume 187.

8. Mazer, B.; Kairy, D.; Guindon, A.; Girard, M.; Swaine, B.; Kehayia, E.; Labbé, D. Rehabilitation living lab in the mall community of practice: learning together to improve rehabilitation, participation and social inclusion for people living with disabilities. Int. J. Environ. Res. Public Health 2015, 12, 4439-4460. doi:10.3390/ijerph120404439.

9. Leminen, S.; Westerlund, M. Towards Innovation in Living Labs Network. Int. J. Prod. Dev. 2012, 17, 43-59.

10. Robles, A.; Hirvikoski, T.; Schuurman, D.; Stokes, L. European Network of Living Labs. 2015. Available online: https://issuu.com/enoll/docs/enoll-print (accessed on 20 September 2019).

11. Living Labs - Living Lab Eindhoven (Netherlands). Available online: http://www.transitsocialinnovation.eu/ sii/living-labs-3 (accessed on the 20 September 2019).

12. Living Labs-Imec Living Labs (Former iMinds Living Labs) (Belgium). Available online: http://www.transitsocialinnovation.eu/sii/living-labs-2 (accessed on the 20 September 2019).

13. Living Labs-Laurea (Finland). Available online: http://www.transitsocialinnovation.eu/sii/living-labs-1 (accessed on the 20 September 2019).

14. Living Lab-Manchester University Living Lab. Available online: http://universitylivinglab.org/ (accessed on the 20 September 2019).

15. Everblock Systems. Available online: https://www.everblocksystems.com (accessed on 20 September 2019).

(C) 2019 by the authors. Licensee MDPI, Basel, Switzerland. This article is an open access article distributed under the terms and conditions of the Creative Commons Attribution (CC BY) license (http://creativecommons.org/licenses/by/4.0/). 